\title{
Risk, Incentives and Insurance : The Pure Theory of Moral Hazard, Some Comments
}

\author{
by Karl Borch *
}

1. It is always a pleasure to read a paper by Professor Stiglitz. My reaction is usually : "I wish I had thought that", or "I wish I had been able to make that point as forcefully as Joe did ". On the other hand it is not always easy to open the discussion on a paper by Professor Stiglitz. He usually presents a whole sequence of new ideas, each of which deserves a separate paper, and it is difficult to pick out just a few points for discussion.

2. One of the assumptions behind the present paper is that in a perfect market, competition will drive profits to zero. It is not obvious that this classical result can be carried over to the case of uncertainty, simply by taking expectations. A simple example may help to make this clear.

Let $x$ be the insurer's profit from an insurance contract, and write $E\{x\}$ and $\operatorname{var}\{x\}$ for the expectation and variance. For a portfolio of a large number of such contracts, the risk, measured by the variance, may be substantial, and we cannot expect an insurer to accept this risk if expected profit is zero, i.e. $E\{x\}=0$.

3. The risk of a direct insurer can be reduced by reinsurance, so assume that after reinsurance transactions the insurer holds only a fraction of $1 / n$ of the risk. Expected profit, and the variance of the retained part of the contract will then be $\frac{1}{n} E\{x\}$ and $\frac{1}{n^{2}} \operatorname{var}\{x\}$ respectively.

If it is possible to "diversify away" the risk in this manner, it is conceivable that a risk averse insurer will accept the contract even if expected profit is approximately zero. In practice middle sized risks are not spread out to the point where each reinsurer carries only an infinitesimal part, but this can be explained by the unavoidable transaction costs, which in any case give a convenient excuse when theoretical models do not agree with observations. The implication is however that the insurer will demand a risk premium, i.e. a positive expected profit, equivalent to the cost of complete diversification.

4. There is however also an element of moral hazard in the diversification. Reinsurers always insist that their transactions are carried out in " the utmost good faith". A reinsurer will accept, without question, the premium rates set by the direct

* Professor at the Norwegian School of Economics and Business Administration, Bergen. 
insurer, as well as his decisions in the settlement of claims. It is not likely that a direct insurer will enjoy such complete confidence unless he carries a significant part of the risk himself. If he retains only an infinitesimal part of the risk for himself, the reinsurers may get wary, and refuse to play. Hence a direct insurer must carry some risk himself to maintain credibility with his reinsurers. This is really his only way to prove that he takes care in his underwriting, and that he does not pass bad risks on to the reinsurers. Clearly he will demand a positive expected profit as compensation for the risk bearing service he provides.

5. There is also some empirical evidence that expected profits cannot be zero for all insurance contracts. Many insurance companies will extend their fire policies to cover damage by earthquakes, against some additional premium. In some parts of the world, for instance in Northern Europe, this extra charge will be insignificant. In parts of California, and in the Tokyo Bay area the premium for the extended cover will be substantial, and may be about the same as the premium for fire insurance. As the probability that a house shall be destroyed by fire must be far higher than the probability of a major earthquake, it seems safe to assume that earthquake insurance will give the insurer a positive expected profit.

6. To me, the economic theory of insurance is essentially the theory of risk bearing, and one of the main problems is to determine the price of the service offered by the risk bearers, i.e. the risk premium in a competitive market. The problem can certainly be studied within the framework of standard economic analysis, but some care is required when the zero-profit condition is introduced.

7. Moral hazard is in some sense connected with transaction costs. A plant manager may not be as diligent as he should in checking that sprinklers are in working order, and that fire extinguishers are in their place, if he knows that all losses due to fire will be covered by the insurer. One must however assume that the insurer is aware of this possibility, and that he will check that the plant has taken all reasonable precautions to prevent fires, and to reduce the damage. Usually the insurance contract will give the insurer a right to carry out such checks without warning whenever he wants. Such checking will however cost money, and the costs must eventually be paid by the insured, in the form of higher premiums. In the end the result may be the same whether the insurer makes frequent inspections of the plant, or simply charges a premium based on the assumption that a well insured plant manager tends to become careless.

8. Let me end by trying to drive this point home with an example more in line with those given by Stiglitz. It is unlikely that I should become a more careless driver if I had full collision insurance on my car. I may however become a worse risk to my insurance company. When I do not want to lend my car to teenagers in the family, it is a very convenient excuse to say that I don't have collision insurance. The insurer does not know my relationship with the younger members of the family, but he knows that I have a legal right to lend my car to anybody who has a valid driver's licence, and he will charge the corresponding premium. This is probably the essence of moral hazard. If you have a legal right to be careless - within reason - the insurer will play a minimax strategy, and assume that you make full use of this right, and charge you accordingly. 